\title{
Peer
}

\section{Microsatellite loci in the tiger shark and cross-species amplification using pyrosequencing technology}

Natália J. Mendes ${ }^{1}$, Vanessa P. Cruz ${ }^{1}$, Fernando Y. Ashikaga ${ }^{1}$, Sâmia M. Camargo ${ }^{1,2}$, Claudio Oliveira ${ }^{1}$, Andrew N. Piercy ${ }^{3}$, George H. Burgess ${ }^{4}$, Rui Coelho ${ }^{5}$, Miguel N. Santos ${ }^{5}$, Fernando F. Mendonça ${ }^{2}$ and Fausto Foresti ${ }^{1}$

${ }^{1}$ Laboratório de Biologia e Genética de Peixes, Universidade Estadual Paulista, Botucatu, São Paulo, Brazil

${ }^{2}$ Laboratório de Genética Pesqueira e Conservação, Institute of Marine Sciences, Universidade Federal de São Paulo, Santos, São Paulo, Brazil

${ }^{3}$ Lake Nona Campus, Valencia College, Orlando, Florida, United States

${ }^{4}$ Florida Museum of Natural History, Florida Program for Shark Research, University of Florida, Gainesville, Florida, United States

${ }^{5}$ IPMA, Portuguese Institute for the Ocean and Atmosphere, Algarve, Portugal

\section{ABSTRACT}

The tiger shark (Galeocerdo cuvier) has a global distribution in tropical and warm temperate seas, and it is caught in numerous fisheries worldwide, mainly as bycatch. It is currently assessed as near threatened by the International Union for Conservation of Nature (IUCN) Red List. In this study, we identified nine microsatellite loci through next generation sequencing (454 pyrosequencing) using 29 samples from the western Atlantic. The genetic diversity of these loci were assessed and revealed a total of 48 alleles ranging from 3 to 7 alleles per locus (average of 5.3 alleles). Cross-species amplification was successful at most loci for other species such as Carcharhinus longimanus, C. acronotus and Alopias superciliosus. Given the potential applicability of genetic markers for biological conservation, these data may contribute to the population assessment of this and other species of sharks worldwide.

Submitted 29 February 2016

Accepted 11 June 2016

Published 30 August 2016

Corresponding author

Fernando F. Mendonça, fernando.mendonca@unifesp.br

Academic editor

James Reimer

Additional Information and Declarations can be found on page 6

DOI 10.7717/peerj.2205

(c) Copyright

2016 Mendes et al.

Distributed under

Creative Commons CC-BY 4.0

OPEN ACCESS
Subjects Aquaculture, Fisheries and Fish Science, Conservation Biology, Genetics, Marine Biology, Zoology

Keywords High-throughput sequencing, Galeocerdo cuvier, Shark, Microsatellites, Population structure

\section{INTRODUCTION}

The tiger shark Galeocerdo cuvier (Péron \& Lesueur, 1822), is a shark from the order Carcharhiniformes and family Carcharhinidae. It has a worldwide distribution in tropical and temperate seas, and is considered a top predator generally requiring large foraging areas (Heupel et al., 2014). Recent data shows that this species can move long distances and occupies different regions, including coastal areas being therefore more susceptible than pelagic sharks to anthropogenic threats (Heupel et al., 2014).

Caught in many world fisheries as bycatch, the tiger shark is currently classified as "Near Threatened" by the International Union for Conservation of Nature (IUCN). 
However, some basic information, such as the characterization of population genetic structure, variability, identification of geographical restrictions to gene flow with possible local populations remains broadly unknown. In light of this, information on their conservation status is difficult to assess. For this reason, molecular markers have been increasingly used in species conservation and management programs, including microsatellite molecular markers (Simple Sequence Repeats-SSR). A range of SSR markers have been developed using the pyrosequencing technique, generating information with millions of base pairs in a single run and in a short period of time.

Specifically for the tiger shark, nine SSR markers were previously developed on specimens from the Hawaiian archipelago (Bernard, Feldheim \& Shivji, 2015), but cross-application was not tested for other shark species yet. Thus, the objectives of this study were to identify other microsatellites for the tiger shark in specimens from the Atlantic, and design additional molecular markers that can now be used in this and other shark species for population genetics studies.

\section{MATERIAL AND METHODS}

\section{Sampling}

In fulfillment of data archiving guidelines (Baker, 2013), primary data have been deposited with Dryad. Samples of tiger shark were collected in landings of the fishing fleet from São Paulo coast $(\mathrm{n}=12)$ and in scientific cruises in the Fernando de Noronha archipelago $(n=6)$ by researchers from the Biosciences Institute of Botucatu, São Paulo State University, and Marine Sciences Institute of the São Paulo Federal University, in Brazil. Additionally, 11 samples were collected from the east coast of Florida by the Florida Program for Shark Research, University of Florida, USA. For evaluating crossamplification we used six samples of Carcharhinus acronotus collected from São Paulo coast, five samples of $C$. longimanus and five samples of Alopias superciliosus, collected in the northeast Atlantic by onboard observers from the Portuguese Institute for the Ocean and Atmosphere (IPMA), Portugal. All sampled tissues were stored in 95\% ethanol to ensure the integrity and quality of tissue for molecular analysis.

\section{GS-FLX pyrosequencing and microsatellite discovery}

The total genomic DNA was extracted from each sample following the protocol described by Ivanova, Dewaard \& Hebert (2006). A sample (voucher: TIG03SP) of $100 \mu \mathrm{g}$ of tigershark DNA from São Paulo coast $(-25.1164,-47.6082)$ was sequenced on a Roche 454 GS FLX sequencer with Titanium platform "Genome sequencer 20 System” (Instituto Agrobiotecnológico de Rosário-INDEAR, Argentina), following procedures described in Margulies et al. (2005).

To isolate microsatellites and design primers for population genetics all sequences of the SSR were compiled using Primer3 (Rozen \& Skaletsky, 1999) and BatchPrimer3 (You et al., 2008). Primers were designed based on the following criteria: primer size of $20 \mathrm{bp}(\min =18, \max =22 \mathrm{bp})$, ideal annealing temperature of $60{ }^{\circ} \mathrm{C}\left(\min =55^{\circ} \mathrm{C}\right.$, $\left.\max =63{ }^{\circ} \mathrm{C}\right)$, GC optimum of $60 \%(\min =40 \%, \max =80 \%)$ and the size of the amplified product ranging from $50-500 \mathrm{bp}$. The sequences were then grouped and aligned 
in the Clustal W software (Thompson, Higgins \& Gibson, 1994), identifying duplicated sequences for the same locus.

\section{Novel microsatellite markers}

The PCR amplifications to test the synthesized primers were performed in a Thermal Cycler Veriti ${ }^{\mathrm{TM}}$ (Applied Biosystems, Foster City, CA, USA) under the following conditions: initial denaturing for $10 \mathrm{~min}$ at $95{ }^{\circ} \mathrm{C} ; 30$ cycles of $94{ }^{\circ} \mathrm{C}$ for $45 \mathrm{~s}$, the primer annealing temperature (TA) was tested from of 51 to $57^{\circ} \mathrm{C}$ for $50 \mathrm{~s} ; 72{ }^{\circ} \mathrm{C}$ for $50 \mathrm{~s}$, and a final extension at $72{ }^{\circ} \mathrm{C}$ for $20 \mathrm{~min}$. The total reaction volume was $10 \mu \mathrm{L}$ and composed of $1.0 \times$ PCR Buffer, $0.25 \mathrm{mM} \mathrm{MgCl}_{2}, 0.05 \mathrm{mM}$ of each dNTP, 0.5 units of Platinum Taq DNA polymerase (InvitrogenCarlsbad, CA, USA), $0.10 \mu \mathrm{M}$ reverse primer, $0.10 \mu \mathrm{M}$ forward primer, and $30 \mathrm{ng}$ of template DNA.

To verify the effectiveness of the reaction and the amplification of the fragments, $1.5 \mu \mathrm{L}$ of the PCR product were subjected to electrophoresis on a $1 \%$ agarose gel. The amplified products were compared with a $1 \mathrm{~Kb}$ plus ladder (Invitrogen), subsequently visualized on a transilluminator and photographed with a digital camera using the Kodak Digital Science software.

Genotyping was done with the M13-tail PCR method of Schuelke (2000). The best loci, that showed high polymorphism and quality of bands, were selected and further analyzed on an ABI 3130xl sequencer (Applied Biosystems, Life Technologies). The allele sizes were determined using ROX 500 (Applied Biosystems) as an internal standard with the software package GeneMapper 3.7 (Applied Biosystems).

We used the software GenAlex analysis 6.1 (Peakall \& Smouse, 2006) to convert our data to run in other analysis programs. Arlequin 3.5 (Excoffier \& Lischer, 2010) was used to calculate heterozygosity, number of alleles, Hardy-Weinberg equilibrium (HWE) and linkage disequilibrium. The program Cervus v.3.0.7 (Marshall et al., 1998) was used to test for the presence of null alleles and estimate, the inbreeding coefficient (Fis) and polymorphism information content (PIC).

\section{RESULTS AND DISCUSSION}

From the genomic material generated by the pyrosequencing technology, a total of 71,059 reads with an average size of $367 \mathrm{bp}$ was obtained, consisting of 26,075,405 nucleotides, which accounts for approximately $0.75 \%$ of the G. cuvier genome, assuming a genome size of $3.44 \mathrm{~Gb}$ (estimated from the size of Rhincodon typus, Read et al., 2015). For the identification of microsatellite sequences, the online software Batch Primer3 was used, and 615 microsatellite loci were identified. A second filtration was subsequently performed with the software Primer 3.0 which identified 159 microsatellite loci. From these, we selected 30 loci which contained the best scores of each primer pair with a size of 15-20 bp, a GC of 40-50\% and little variation in the annealing temperature in the PCR reaction. Of these, 20 pairs of primers were synthesized and tested, nine being polymorphic with one trinucleotide and eight dinucleotide primers (Table 1). The sequences for polymorphic microsatellite markers in this study have been deposited in GenBank (Accession numbers: KT598263-KT598271). 
Table 1 General information about the microsatellite analysis.

\begin{tabular}{ll} 
Analyzes & N of sequences \\
\hline Number of reads & 71.059 \\
Selection of microsatellites (using BatchPrimer3) & 615 \\
Secondary selection of microsatellite (using Primer 3.0) & 159 \\
Amplification and control of PCR product on agarose gel & 30 \\
Microsatellite loci to synthesize with fluorescent dye & 20 \\
Polymorphism test with capillary sequencer & 10 \\
Microsatellite loci in linkage equilibrium & 9 \\
\hline
\end{tabular}

Table 2 Data for microsatellite loci of the cross-amplification in Carcharhinus longimanus, Carcharhinus acronotus and Alopias superciliosus.

\begin{tabular}{|c|c|c|c|c|c|c|}
\hline \multicolumn{3}{|c|}{ C. acronotus } & \multicolumn{2}{|c|}{ C. longimanus } & \multicolumn{2}{|c|}{ A. superciliosus } \\
\hline Loci & $\mathrm{Na}$ & Range (bp) & $\mathrm{Na}$ & Range (bp) & $\mathrm{Na}$ & Range (bp) \\
\hline TIG_1 & 2 & $116-118$ & 2 & $118-134$ & 2 & $104-118$ \\
\hline TIG_5 & 3 & $260-264$ & 2 & $331-335$ & 2 & $265-273$ \\
\hline TIG_7 & 2 & $170-180$ & 2 & $162-170$ & 3 & $152-170$ \\
\hline TIG_10 & 2 & $251-253$ & 1 & 304 & 1 & 307 \\
\hline TIG_12 & 2 & $296-364$ & 2 & $246-296$ & 2 & $372-418$ \\
\hline TIG_15 & 1 & 336 & 3 & $290-310$ & 2 & $288-312$ \\
\hline TIG_17 & 3 & $242-270$ & 2 & $210-224$ & 1 & 268 \\
\hline TIG_19 & 0 & 0 & 1 & 316 & 2 & $386-394$ \\
\hline TIG_25 & 1 & 396 & 1 & 358 & 2 & $388-398$ \\
\hline
\end{tabular}

Note:

Na, number of alleles.

The application of the developed markers resulted in 48 alleles, with a minimum of 3 (TIG_25) to 7 (TIG_1, TIG_7, TIG_12) and average of 5.3 alleles per loci. Transferability tests of the markers in other species showed positive amplification in C. longimanus, Alopias superciliosus and C. acronotus. For the C. acronotus, two loci were polymorphic (TIG_17, TIG_5), and for C. longimanus and Alopias superciliosus only one polymorphic locus were observed in five samples of each species, TIG_15 and TIG_7, respectively (Table 2).

In tiger shark the observed heterozygosity ( $\mathrm{Ho})$ and expected heterozygosity $(\mathrm{He})$ ranged from 0.16 (TIG_17) to 1.0 (TIG_10) and 0.20 (TIG_25) to 0.72 (TIG_7), respectively (Table 3). The Ho was higher than He, suggesting an excess of heterozygotes relative to the model of HWE. Significant differences from HWE after Bonferroni correction $(\mathrm{p}<0.01)$ were detected in only two loci (TIG_10 and TIG_17). The deviation in the HWE for locus TIG_17 (0.715) can be explained by a significant value in intrapopulation Fis (Kordicheva et al., 2010). This locus was the only one with a positive value for the Fis, and may be evidence of a heterozygous deficiency (Holsinger \& Weir, 2009), resulting in a decrease in genetic variability. 
Table 3 Data for microsatellite loci in the tiger shark, Galeocerdo cuvier.

\begin{tabular}{|c|c|c|c|c|c|c|c|c|c|c|c|c|}
\hline Loci & Primer sequence $\left(5^{\prime} \rightarrow 3^{\prime}\right)$ & MOTIF & $\mathrm{T}^{\circ} \mathrm{C}$ & $\mathbf{N}$ & $\mathrm{Na}$ & Range (bp) & Ho & $\mathrm{He}$ & HWE & Fis & PIC & F (Null) \\
\hline TIG_1 & $\begin{array}{l}\text { F_CTCTTGACGGTGCTCGATC } \\
\text { R_AATGGCAACTTTTCCTGTCC }\end{array}$ & $(\mathrm{AC}) 10$ & 53 & 29 & 7 & $116-154$ & 0.758 & 0.642 & 0.711 & -0.184 & 0.710 & -0.194 \\
\hline TIG_5 & $\begin{array}{l}\text { F_GCCAGCATCCATTCATACAG } \\
\text { R_AGAGGGAAGTGGTGTGTGGT }\end{array}$ & $(\mathrm{CT}) 8$ & 51 & 26 & 4 & $203-257$ & 0.384 & 0.337 & 1.000 & -0.141 & 0.589 & -0.239 \\
\hline TIG_7 & $\begin{array}{l}\text { F_CACCAACСТCСССАТСАС } \\
\text { R_CAGACATTCСТССТССАТСC }\end{array}$ & $(\mathrm{AC}) 15$ & 57 & 27 & 7 & $169-183$ & 0.925 & 0.726 & 0.318 & -0.280 & 0.811 & -0.101 \\
\hline TIG_10 & $\begin{array}{l}\text { F_CTCAGCAGGTCTGGACAACA } \\
\text { R_GGTGGTAGGAACATGGAACG }\end{array}$ & (GT) 10 & 59 & 29 & 5 & $256-276$ & 1.000 & 0.655 & 0.000 & -0.539 & 0.608 & -0.245 \\
\hline TIG_12 & $\begin{array}{l}\text { F_TGCCATGAGTGCTGTTTTTC } \\
\text { R_TGCCGCATTGTTACTGCTAC }\end{array}$ & $(\mathrm{CA}) 11$ & 53 & 28 & 7 & $364-376$ & 0.535 & 0.520 & 0.543 & -0.030 & 0.682 & -0.213 \\
\hline TIG_15 & $\begin{array}{l}\text { F_AACTGCCAAAAGGGACAAGA } \\
\text { R_GTAAGCCCAACAGACCATCC }\end{array}$ & (TG) 15 & 55 & 25 & 6 & $231-241$ & 0.520 & 0.463 & 0.675 & -0.124 & 0.650 & -0.233 \\
\hline TIG_17 & $\begin{array}{l}\text { F_TGAAGCTAACGAGGGGTCTG } \\
\text { R_AGCGCAGAAGATCAAGAGGA }\end{array}$ & (GT) 11 & 57 & 25 & 4 & $268-286$ & 0.160 & 0.554 & 0.000 & 0.715 & 0.734 & -0.138 \\
\hline TIG_19 & $\begin{array}{l}\text { F_TGCTTGTGTCTGAGGTGAGTG } \\
\text { R_TTGGAGGTTCAATCCGAGAC }\end{array}$ & (TG) 10 & 53 & 27 & 5 & $337-353$ & 0.555 & 0.443 & 0.677 & -0.260 & 0.627 & -0.214 \\
\hline TIG_25 & $\begin{array}{l}\text { F_CCGTGCCTATGTGGATTTCT } \\
\text { R_CTTGAAGAGAGTGGGCGAAG }\end{array}$ & (CCT)5 & 55 & 27 & 3 & $331-349$ & 0.222 & 0.206 & 1.000 & -0.075 & 0.511 & -0.285 \\
\hline
\end{tabular}

Notes:

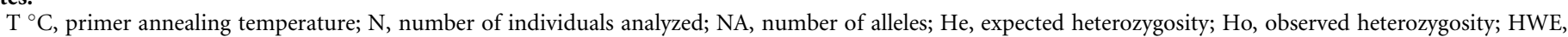
probability of departure from Hardy-Weinberg equilibrium; Fis, inbreeding coefficient; PIC, polymorphism information content; F (Null), null alleles.

Imbalance values in Hardy-Weinberg equations when considering microsatellite locus may be due to the presence of null alleles (Kordicheva et al., 2010). However, the presence of null allele was not detected in the present study, indicating that the markers developed are of high quality. Further, the PIC was highly informative for all the loci (PIC > 0.5), also indicating a high quality marker (Botstein et al., 1980).

In the present study, the average expected heterozygosity was approximately 0.50 and the average observed heterozygosity was 0.55 . The levels of genetic variability seen in this study may be due to population differences resulting from remote sample locations. This is to be expected given that the samples are coming from different oceans and the finding of significant differences in the levels of heterozygosity among different groups would not be unforeseen.

\section{ACKNOWLEDGEMENTS}

The authors thank all those who contributed to this study, including the researchers who carried out the sample collection in the Fernando de Noronha Archipelago and the fishermen for facilitating tissue collection during landings on the São Paulo coast. Sampling and data collection from the Portuguese fishery were obtained and supported by the Programa Nacional de Amostragem Biologica (PNAB) within the scope of the EU Data Collection Framework (DCF). The authors are grateful to all fishery observers and longline skippers that helped collect samples for this study. 


\section{ADDITIONAL INFORMATION AND DECLARATIONS}

\section{Funding}

R. Coelho is supported by an Investigador-FCT contract from the Portuguese Foundation for Science and Technology (FCT, Fundação para a Ciência e Tecnologia) supported by the EU European Social Fund and the Programa Operacional Potencial Humano (Ref: IF/00253/2014). N.J. Mendes was supported by a grant from Foundation for Research Support of the São Paulo State-FAPESP (Ref: 2013/14555-4). This work was funded by FAPESP (Ref: BIOTA 2011/23787-0). The funders had no role in study design, data collection and analysis, decision to publish, or preparation of the manuscript.

\section{Competing Interests}

The authors declare that they have no competing interests.

\section{Author Contributions}

- Natália J. Mendes conceived and designed the experiments, performed the experiments, analyzed the data, contributed reagents/materials/analysis tools, wrote the paper, prepared figures and/or tables, reviewed drafts of the paper.

- Vanessa P. Cruz conceived and designed the experiments, performed the experiments, analyzed the data, wrote the paper, prepared figures and/or tables, reviewed drafts of the paper.

- Fernando Y. Ashikaga conceived and designed the experiments, performed the experiments, analyzed the data, prepared figures and/or tables, reviewed drafts of the paper.

- Sâmia M. Camargo performed the experiments, analyzed the data, reviewed drafts of the paper.

- Claudio Oliveira analyzed the data, contributed reagents/materials/analysis tools, reviewed drafts of the paper.

- Andrew N. Piercy contributed reagents/materials/analysis tools, reviewed drafts of the paper.

- George H. Burgess contributed reagents/materials/analysis tools, reviewed drafts of the paper.

- Rui Coelho analyzed the data, contributed reagents/materials/analysis tools, reviewed drafts of the paper.

- Miguel N. Santos contributed reagents/materials/analysis tools, reviewed drafts of the paper.

- Fernando F. Mendonça conceived and designed the experiments, analyzed the data, contributed reagents/materials/analysis tools, wrote the paper, prepared figures and/or tables, reviewed drafts of the paper.

- Fausto Foresti analyzed the data, contributed reagents/materials/analysis tools, reviewed drafts of the paper. 


\section{Animal Ethics}

The following information was supplied relating to ethical approvals (i.e., approving body and any reference numbers):

Institutional Review Board Ministério do Meio Ambiente-MMA approval number: 50463-1.

\section{DNA Deposition}

The following information was supplied regarding the deposition of DNA sequences:

GenBank

BankIt1851998 Seq1 KT598263

BankIt1851998 Seq2 KT598264

BankIt1851998 Seq3 KT598265

BankIt1851998 Seq4 KT598266

BankIt1851998 Seq5 KT598267

BankIt1851998 Seq6 KT598268

BankIt1851998 Seq7 KT598269

BankIt1851998 Seq8 KT598270

BankIt1851998 Seq9 KT598271.

\section{REFERENCES}

Baker CS. 2013. Journal of heredity adopts joint data archiving policy. Journal of Heredity 104(1):1 DOI 10.1093/jhered/ess137.

Bernard AM, Feldheim KA, Shivji MS. 2015. Isolation and characterization of polymorphic microsatellite markers from a globally distributed marine apex predator, the tiger shark (Galeocerdo cuvier). Conservation Genetics Resources 7(2):509-511

DOI 10.1007/s12686-014-0408-0.

Botstein D, White RL, Skolnick M, Davis RW. 1980. Construction of a genetic linkage map in man using restriction fragment length polymorphisms. American Journal of Human Genetics 32(3):314-331.

Excoffier L, Lischer HEL. 2010. Arlequin suite ver 3.5: A new series of programs to perform population genetics analyses under Linux and Windows. Molecular Ecology Resources 10:564-567 DOI 10.1111/j.1755-0998.2010.02847.x.

Heupel M, Knip D, Simpfendorfer C, Dulvy N. 2014. Sizing up the ecological role of sharks as predators. Marine Ecology Progress Series 495:291-298 DOI 10.3354/meps10597.

Holsinger KE, Weir BS. 2009. Genetics in geographically structured populations: defining, estimating and interpreting FST. Nature Reviews Genetics 10(9):639-650 DOI 10.1038/nrg2611.

Ivanova NV, Dewaard JR, Hebert PDN. 2006. An inexpensive, automation-friendly protocol for recovering high-quality DNA. Molecular Ecology Notes 6:998-1002 DOI 10.1111/j.1471-8286.2006.01428.x.

Kordicheva SY, Rubtsova GA, Shitova MA, Shaikhaev GO, Afanasiev KI, Zhivotovsky LA. 2010. Search for null alleles at the microsatellite locus of chum salmon (Oncorhynchus keta Walbaum). Russian Journal of Genetics 46(8):1019-1022 DOI 10.1134/S1022795410080168.

Margulies M, Egholm M, Altman WE, Attiya S, Bader JS, Bemben LA, Berka J, Braverman MS, Chen Y-J, Chen Z, Dewell SB, Du L, Fierro JM, Gomes XV, Godwin BC, He W, Helgesen S, Ho CH, Irzyk GP, Jando SC, Alenquer MLI, Jarvie TP, Jirage KB, Kim J-B, Knight JR, 
Lanza JR, Leamon JH, Lefkowitz SM, Lei M, Li J, Lohman KL, Lu H, Makhijani VB, McDade KE, McKenna MP, Myers EW, Nickerson E, Nobile JR, Plant R, Puc BP, Ronan MT, Roth GT, Sarkis GJ, Simons JF, Simpson JW, Srinivasan M, Tartaro KR, Tomasz A, Vogt KA, Volkmer GA, Wang SH, Wang Y, Weiner MP, Yu P, Begley RF, Rothberg JM. 2005. Genome sequencing in microfabricated high-density picolitre reactors. Nature 437(7057):376-380 DOI 10.1038/nature03959.

Marshall TC, Slate J, Kruuk LEB, Pemberton JM. 1998. Statistical confidence for likelihood-based paternity inference in natural populations. Molecular Ecology 7(5):639-655 DOI 10.1046/j.1365-294x.1998.00374.x.

Peakall ROD, Smouse PE. 2006. GENALEX 6: genetic analysis in Excel. Population genetic software for teaching and research. Molecular Ecology Notes 6(1):288-295 DOI 10.1111/j.1471-8286.2005.01155.x.

Read TD, Petit RA III, Joseph SJ, Alam MT, Weil R, Ahmad M, Bhimani R, Vuong JS, Haase CP, Webb H, Dove ADM. 2015. Draft sequencing and assembly of the genome of the world's largest fish, the whale shark: Rhincodon typus Smith 1828. PeerJ PrePrints 3:e837v1

DOI 10.7287/peerj.preprints.837v1.

Rozen S, Skaletsky H. 1999. Primer3 on the WWW for General Users and for Biologist Programmers. Totowa: Humana Press Inc.

Schuelke M. 2000. An economic method for the fluorescent labeling of PCR fragments. Nature Biotechnology 18(2):233-234 DOI 10.1038/72708.

Thompson JD, Higgins DG, Gibson TJ. 1994. CLUSTAL W: improving the sensitivity of progressive multiple sequence alignment through sequence weighting, position-specific gap penalties and weight matrix choice. Nucleic Acids Research 22(22):4673-4680

DOI 10.1093/nar/22.22.4673.

You FM, Huo N, Gu YQ, Luo MC, Ma Y, Hane D, Lazo GR, Dvorak J, Anderson OD. 2008. BatchPrimer3: a high throughput web application for PCR and sequencing primer design. BMC Bioinformatics 9(1):253 DOI 10.1186/1471-2105-9-253. 